\title{
Karakterisasi Mekanik Komposit Matriks Polipropilena High Impact Dengan Serat Alam Acak Dengan Metode Hand Lay Up Untuk Komponen Automotive
}

\author{
Alfan Ekajati Latief, Nuha Desi Anggraeni, Dedy Hernady \\ Jurusan Teknik Mesin, Fakultas Teknologi Industri, ITENAS, Bandung \\ Email: alfanekajati@gmail.com
}

\begin{abstract}
ABSTRAK
Serat alam yang berfungsi sebagai penguat memiliki sifat yang lebih ringan, mudah dibentuk, tahan korosi, harga murah dan memiliki kekuatan yang sama dengan material logam. Serat bahan alami yang memiliki kekuatan tarik, tekan dan impak yang baik diantaranya serat rami dan daun nanas. Untuk matriks Polipropilena high impact (PPHI) yang banyak digunakan dalam industri otomotif.. Pada penelitian ini dipelajari pengaruh fraksi volume serat alami terhadap sifat mekanik komposit PPHI berpenguat serat alami. Komposit PPHI dibuat dengan menggunakan metode Hand Lay Up pada temperatur $250^{\circ} \mathrm{C}$ dengan fraksi volume serat alami sebesar 10\%, dimana serat dibuat digunting halus hingga memiliki ukuran mesh 120/170, 170/200 dan dibawah 200 mesh, Kekuatan tarik komposit diukur dengan mengacu pada standar ASTM 3039, kekuatan tekan diukur mengacu pada ASTM D 695. Harga Impak dari komposit diukur dengan mengacu pada ASTM D 6110-04. Pada penelitian ini dapat disimpulkan, fraksi volume $10 \%$ serat alami yang baik ketika dicampur dengan matriks polipropilena high impact adalah serat nanas dengan meshing 170/200 dapat meningkatkan kekuatan tarik PPHI sebesar $40 \%$ dan meningkatkan harga impak PPHI sebesar 50,8\% jika dilihat penelitan sebelumnya yakni menggunakan serat rami dibawah mesh 1200 dengan matriks PPHI.
\end{abstract}

Kata Kunci: Rami, Daun Nanas, Polipropilena High Impact, Hand Lay Up.

\begin{abstract}
Natural fibers that function as reinforcement have lighter properties, are easily formed, are corrosion resistant, are cheap and have the same strength as metal materials. Natural fiber which has good tensile, compressive and impact strength including Ramie and pineapple leaves. For high impact polypropylene matrix (PPHI) which is widely used in the automotive industry. In this study the effect of volume fraction of natural fibers on the mechanical properties of PPHI composites with natural fiber reinforced properties was studied. PPHI composites are made using the Hand Lay Up method at a temperature of $250^{\circ} \mathrm{C}$ with a volume fraction of natural fibers of 10\%, where fibers are made finely shaved to have a mesh size of 120/170, 170/200 and below 200 mesh, the tensile strength of the composite is measured by reference to the standard ASTM 3039, compressive strength measured refers to ASTM D 695. The impact price of the composite is measured with reference to ASTM D 6110-04. In this study it can be concluded, a good volume fraction of $10 \%$ natural fiber when mixed with high impact polypropylene matrix is pineapple fiber with meshing 170/200 can increase the tensile strength of PPHI by $40 \%$ and increase the impact price of PPHI by $50.8 \%$ if seen by research previously that used hemp fiber under mesh 1200 with PPHI matrix.
\end{abstract}

Keywords: Ramie Pineapple, High Impact Polypropylene, Hand Lay Up. 


\section{PENDAHULUAN}

Komposit polimer berpenguat serat hayati sering dimanfaatkan dalam aplikasi otomotif terutama untuk aplikasi interior[1]. Saat ini, didalam dunia otomotif pemanfaatan komposit polimer berpenguat serat masih didominasi oleh serat gelas[2]. Namun secara perlahan pemanfaatan komposit polimer berpenguat serat gelas mulai digantikan oleh komposit polimer berpenguat serat hayati karena serat hayati memiliki sifat mekanik yang cukup baik, murah, ringan serta ramah lingkungan [3]

Penggunaan bahan komposit polimer berserat alam dalam bidang industri otomotif saat ini pula mengalami perkembangan yang pesat serta berusaha menggeser keberadaan bahan komposit polimer sintetis yang sudah biasa dipergunakan sebagai penguat pada bahan komposit seperti $E$ Glass, Carbon,dan Silicone Carbide. Penggunaan komposit polimer dalam produksi komponenkomponen mobil telah terbukti mampu menyeimbangkan fungsi mobil seperti mengurangi berat dan menjaga keselamatan penumpang [4].

Polipropilena high impact (PPHI) merupakan salah satu polimer yang umum digunakan dalam industri otomotif Indonesia[5]. Ketahanan terhadap beban impak yang tinggi menjadikan PPHI sangat menjanjikan untuk dimanfaatkan sebagai bahan pengikat pada komposit polimer berpenguat serat hayati. Studi mengenai pemanfaatan PPHI sebagai bahan pengikat pada komposit polimer berpenguat serat hayati masih belum banyak dipelajari. Pada penelitian umunya telah, dilakukan studi sifat tarik dan sifat impak dari komposit PPHI berpenguat serat rami, dimana PPHI dimanfaatkan sebagai bahan pengikat dan serat rami berfungsi sebagai bahan penguat dengan berbagai fraksi volume, dan fraksi volume $10 \%$ PPHI dan penambahan serat rami meshing dibawah 1200 dapat meningkatkan kekuatan tarik PPHI sebesar 21\%dan meningkatkan harga impak PPHI sebesar 15.5\%.[5]

Selain serat rami dilihat dari rata-rata hasil produksi serat di Indonesia bahwa serat nanas memilki nilai yang paling tinggi [4], dan bila ditinjau dari sifat mekanik yakni modulus elastisitasnya lebih baik dibandingkan dengan rami[6], oleh karena itu dilakukan studi sifat mekanik menggunakan pengujian tarik, bending dan Impak untuk komposit baerpenguat serat alam rami dan nanas dengan variasi meshing 120/170, 170/200 dan dibawah 200 akan dicampur dengan matrik PPHI fraksi volume $10 \%$ sehingga akan mendapatkan serat alam dengan meshing yang optimal.

\section{METODOLOGI}

\subsection{Metodologi Penelitian}

Secara garis besar, metode kerja yang dilakukan dalam penelitian ini terdiri dari beberapa tahapan yang tergambarkan pada diagram alir berikut: 


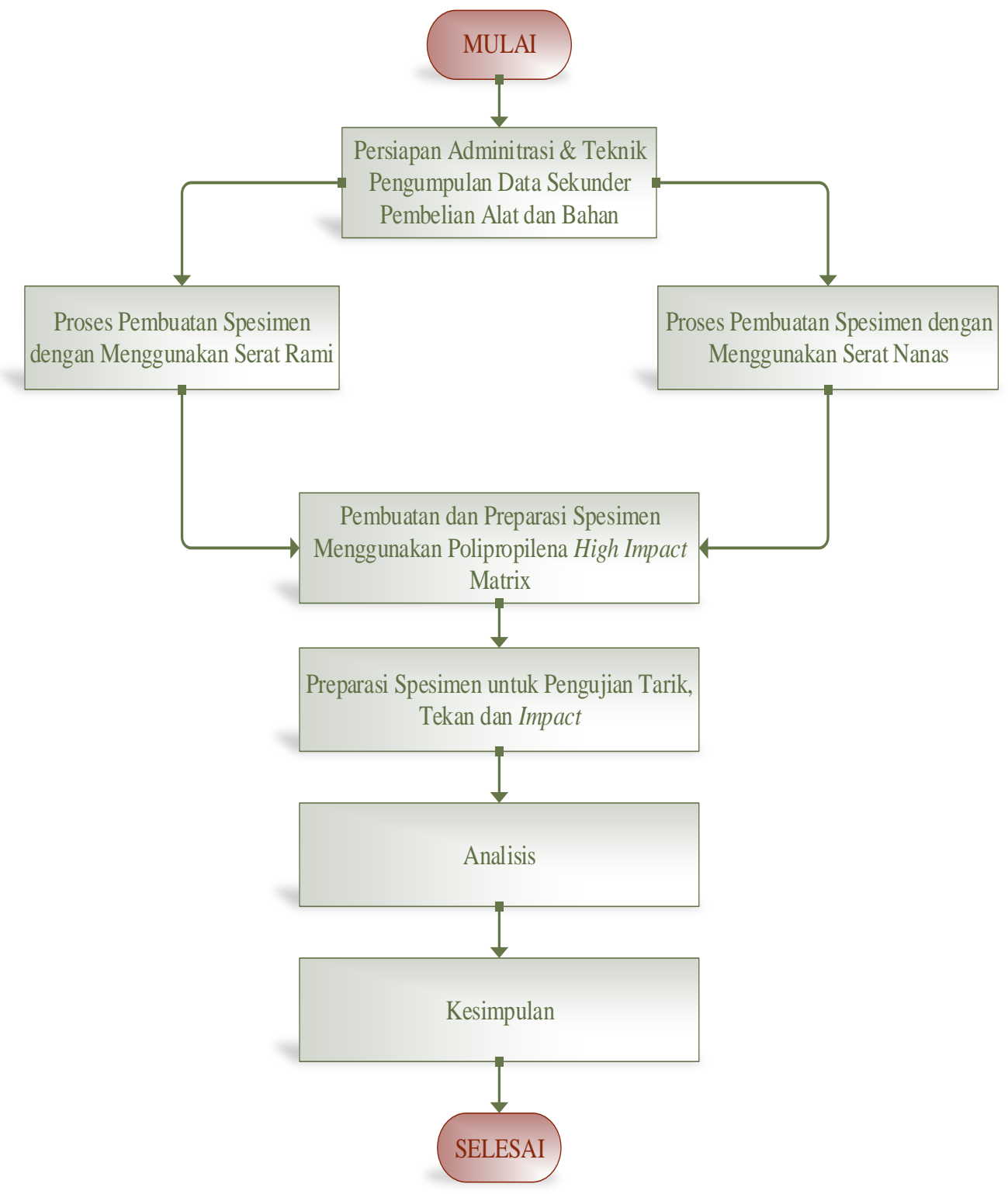

Gambar 1. Flow Chart Proses Optimasi Serat Alam

\subsection{Material}

Material yang digunakan adalah Serat rami dan daun nanas yang diperoleh dari Malang dan Subang, Indonesia sedangkan Pelet polipropilena high impact (PPHI) diperoleh dari PT. Chandra Asri Petrochemical. Untuk material cetakan yang digunakan aluminium seri 7075.

\subsection{Preparasi Serat}

Melakukan pembuatan cetakan dengan bahan Aluminium, dengan menggambar desain terlebih dahulu yang menggunakan software solidwork, lalu membuat program CNC menggunakan software NX Siemens dan proses machinning menggunakan mesin CNC MCV 300 yang ada di lab CNC Itenas.

Serat rami dipotong sepanjang $25 \mathrm{~cm}$ dan disisir secara manual dengan menggunakan sisir kawat khusus serat hingga serat rami saling terpisah sedangkan untuk daun nanas dikeringkan sampai kering menggunakan oven pada temperatur $200^{\circ} \mathrm{C}$ selama 6 jam. Kemudian serat alami yang 
telah saling digunting halus dan dipanaskan, dilakukan pemisahan hingga memilikimesh 120/170, 170/200 dan mesh dibawah 200.

Serat alam yang telah digunting halus dicampurkan dengan pelet PPHI dengan fraksi volume serat terhitung sebesar $10 \%$. Kemudian campuran serat dan pelet PPHI dimasukkan kedalam cetakan menggunakan metode hand lay up pada temperatur $250^{\circ} \mathrm{C}$.

\subsection{Pengujian}

Proses pengujian ini dilakukan dengan cara melihat berat dari tiap komposit dan uji mekanik dengan cara melakukan uji tarik, bending dan impak pada komposit yang akan dilaksankan di Laboratorium Metalurgi Itenas dan ITB.

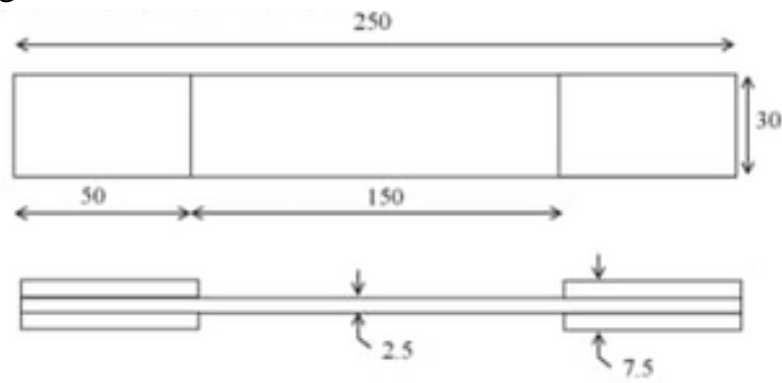

Gambar 2 ASTM 3039 pesimen Uji Tarik
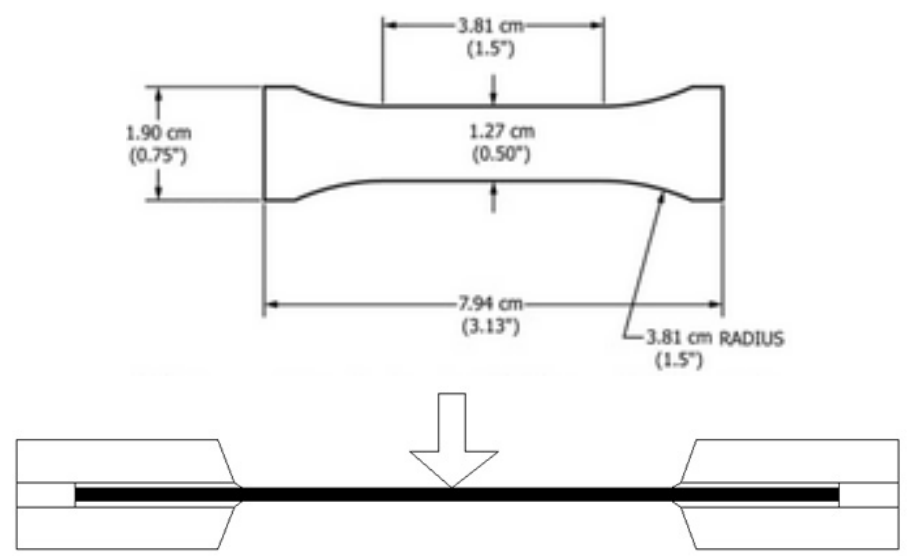

Gambar 3. ASTM D 695 Spesimen Uji Lentur (Bending)

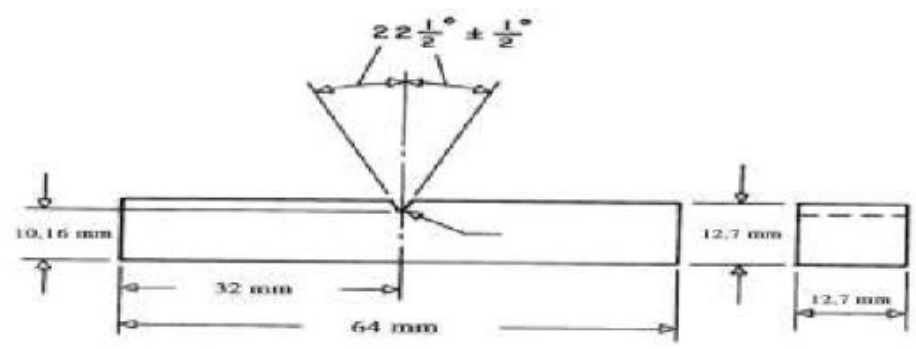

Gambar 4. ASTM D 6110-04 Spesimen Uji Impak 


\section{HASIL DAN PEMBAHASAN}

\subsection{Uji Tarik}

Spesimen uji tarik komposit PPHI yang diperkuat serat rami yang dibuat dengan mesin Hand Lay Up dapat dilihat pada Gambar 1

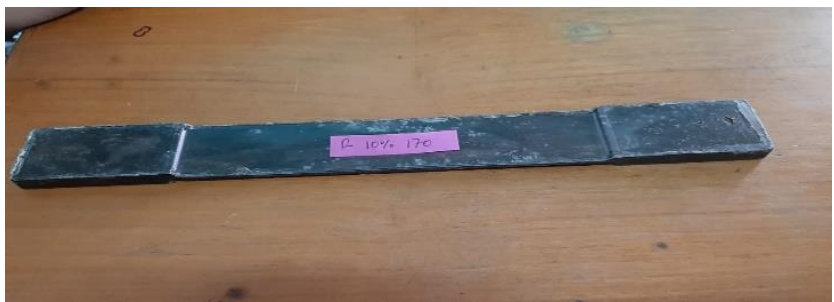

Gambar 5. Spesimen uji tarik komposit PPHI yang diperkuat serat alam

Dari hasil pengujian dan pembahasan data yang diperoleh pada komposit PPHI serat alam serta datakekuatan tarik serat rami yang diperoleh dari literatur [6] bisa dilihat dari gambar dibawah ini

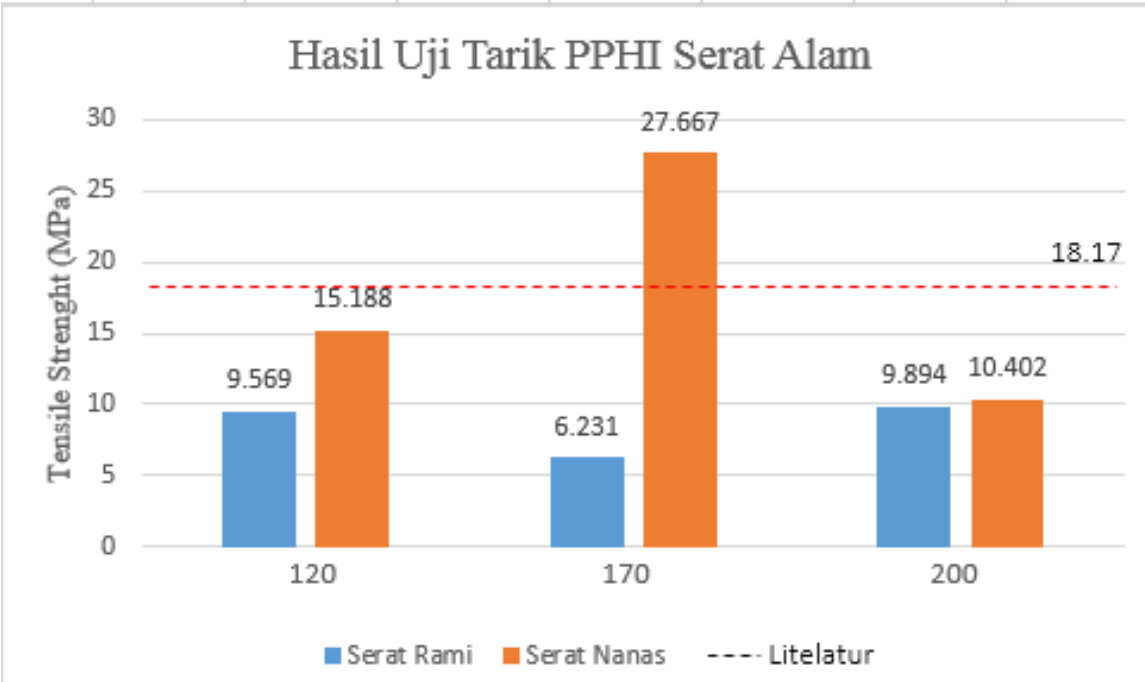

Gambar 6. Grafik Hasil Uji Tarik PPHI Serat Alam

Dari grafik diatas juga dapat disimpulkan bahwa pada spesimen PPHI serat rami dengan mesh 170 memliki nilai yang rendah dibanding dengan spesimen PPHI serat rami 120 dan 200 . berbanding terbalik dengan spesimen PPHI serat nanas mesh 170 memilki nilai kekuatan tarik yang tinggi sebesar 27.667 MPa dibanding dengan spesimen PPHI serat nanas mesh 120 dan 200.

Pada komposit PPHI serat rami mesh 170 memiliki nilai kekuatan yang rendah disebabkan karena banyaknya void yang terjadi pada komposit itu, yang menyebabkan komposit itu memilki sifat mekanik yang kurang baik.

Dari grafik diatas juga terlihat bahwa komposit PPHI serat nanas memiliki nilai kekuatan yang baik dibanding dengan komposit serat rami, bahkan pada komposit PPHI serat nanas mesh 170 
memilki nilai yang cukup tinggi sebesar 27.667 MPa dan melebihi litelatur yang memilki nilai kekuatan tarik sebesar 18.17 Mpa. Pada fraksi volume 10\%. Salah satu yang mempengaruhi nilai kekuatan serat nanas dibanding dengan serat rami yaitu diameter pada serat nanas tersebut.serat nanas memilki diameter $98 \mu \mathrm{m}$ sedangkan serat rami sebesar $49 \mu \mathrm{m}$.

Hasil Uji Bending PPHI Serat Alam

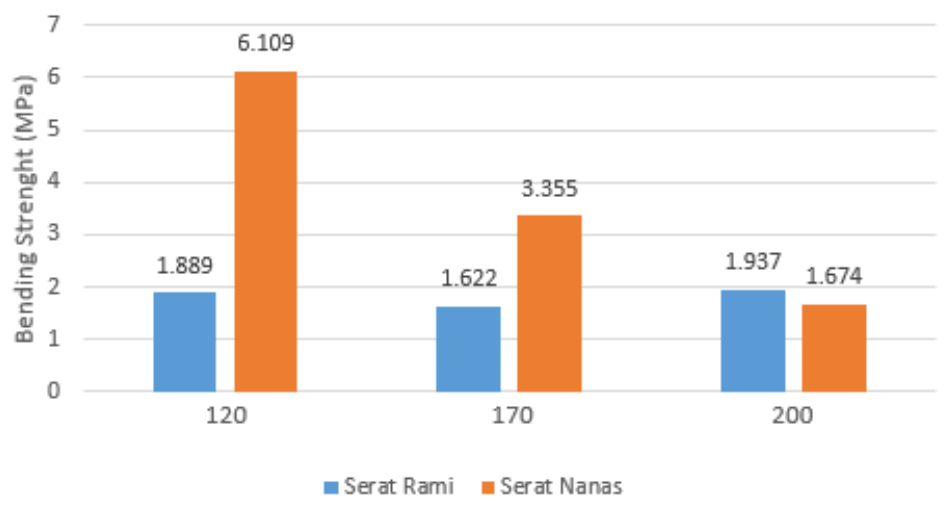

Gambar 7. Grafik Hasil Uji Bending PPHI Serat Alam

Pada komposit PPHI serat nanas memliki nilai yang menurun dari mesh 120, 170 dan 200, dan pada mesh 120 memilki nilai yang cukup baik sebesar 6.109 MPa sedangkan nilai terkecil pada komposit $200 \mathrm{MPa}$ sebesar 1.674 MPa. Banyak faktor yang mempengaruhi menurunnya kekuatan bending, salahsatunya dari ketidakhomogenan pada matriks dan serat yang mengakibatkan komposit memliki sfiat mekanik yang kurang baik. Selain ketidakhomogenan juga bisa sebabkan oleh ukuran panjang dari serat tersebut.

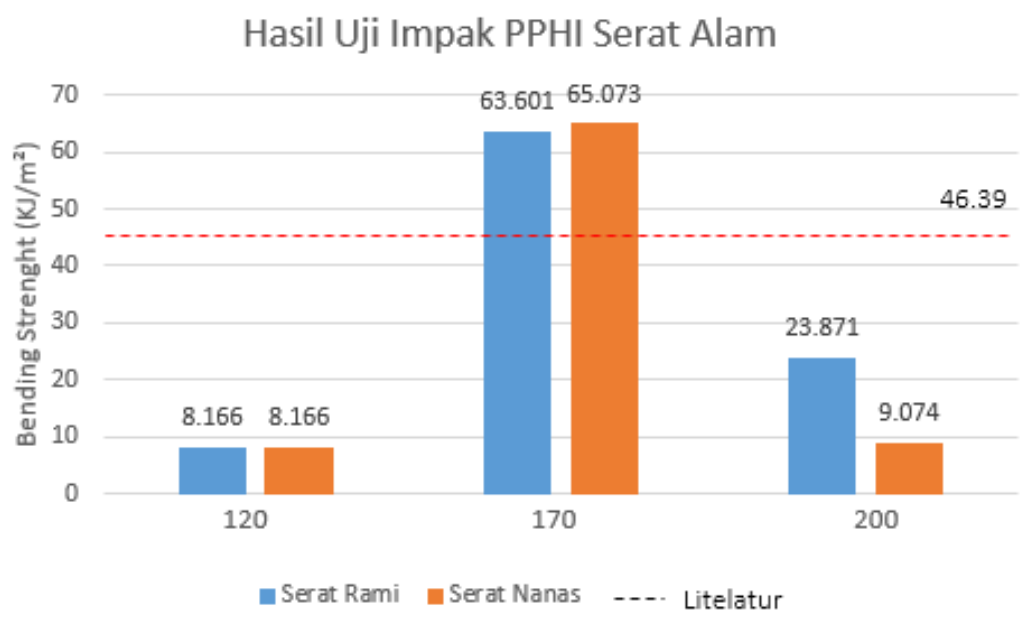

Gambar 8. Grafik Hasil Uji Impak PPHI Serat Alam

Pada grafik diatas juga dapat dilhat bahwa pada PPHI serat rami maupun nanas pada mesh 120 dan 200 memilki nilai yang rendah dibanding dengan mesh 170. Yang di sebabkan oleh banyak nya porositas dan ketidakhomogenan antara serat dengan matrilks, porositas dan ketidakhomoonen ini lah yang menyebabkan tidak banyaknya energi impak yang terserap oleh komposit itu dan menyebabkan nilai kekuatan impak rendah. Sedangkan pada komposit PPHI serat alam mesh 170 memliki nilai yang cukup tinggi, sebesar $63.601 \mathrm{KJ} / \mathrm{m}^{2}$ untuk serat rami dan 65.073 untuk serat nanas. 
Pada grafik diatas juga dapat disimpulkan bahwa komposit PPHI serat alam pada mesh 120 dan 200 memiliki kuliatas sifat mekanik yang baik pada kekuatan tarik dan bending, namun pada komposit PPHI serat alam mesh 170 memilki nilai kekuatan impak yang baik dibanding mesh 120 dan 200.

\section{KESIMPULAN}

Dari penelitian ini dapat disimpulkan bahwa penambahan serat rami dan nanas dapat mempengaruhi sifat tarik dan sifat impak dari polimer PPHI. Pada penelitian ini, fraksi volume $10 \%$ serat alami yang baik ketika dicampur dengan matriks polipropilena high impact adalah serat nanas dengan meshing 170/200 dapat meningkatkan kekuatan tarik PPHI sebesar $40 \%$ dan meningkatkan harga impak PPHI sebesar 50,8 \% dari penelitian sebelumnya yakni menggunakan serat rami dibawah mesh 1200 dengan matriks PPHI.

\section{DAFTAR PUSTAKA}

[1] I. E. Aková, "DEVELOPEMENT OF NATURAL FIBER REINFORCED POLYMER COMPOSITES,” pp. 2011-2013, 2013.

[2] M. Pervaiz, S. Panthapulakkal, B. Kc, M. Sain, and J. Tjong, "Emerging Trends in Automotive Lightweighting through Novel Composite Materials," Mater. Sci. Appl., no. March, 2016.

[3] R. P. Venkatesh and K. Ramanathan, “Tensile, Flexual , Impact and Water Absorption Properties of Natural Fibre Reinforced Polyester Hybrid Composites,” vol. 24, no. 117, pp. 90-94, 2016.

[4] M. Sulaiman, U. Islam, and R. Rahmat, "KAJIAN POTENSI PENGEMBANGAN MATERIAL KOMPOSIT POLIMER DENGAN,”Semin. Nas. Tek. Mesin, no. November, 2018.

[5] Mardiyati, "Sifat Tarik Dan Sifat Impak Komposit Polipropilena High Impact Berpenguat Serat Rami Acak Yang Dibuat Dengan Metode Injection Molding," ITB J. Publ. ISSN0852-6095, vol. 26, no. 1, pp. 8-16, 2017.

[6] K. Srinivas, A. Lakshumu, and A. Pradesh, "A Review on Chemical and Mechanical Properties of Natural Fiber Reinforced Polymer Composites,” Int. J. Performability Eng., vol. 13, no. 2, pp. 189-200, 2017. 